\title{
Avaliação do teor de Cumarina e atividade antifúngica de frações de óleo de Cumaru
}

Os cumaruzeiros são árvores neotropicais originárias de países da América Central e América do Sul. Os frutos destacam-se quanto às potencialidades comerciais e fitoterápicas, e suas sementes, há mais de um século, são comercializadas por extrativistas da Amazônia. Este estudo teve por objetivo analisar o teor de cumarina (1,2-benzopirona) e a atividade antifúngica de fraç̃oses de óleo obtidas de sementes de cumaru produzidas no município de Alenquer, Pará, Brasil. As frações foram obtidas por extrações sucessivas à frio, tendo como solventes Hexano P.A., Diclorometano P.A., e Álcool Etílico P.A. a $96 \%$. 0 teor da 1,2-benzopirona nas frações foi analisado quimicamente por Cromatografia em Camada Delgada (CCD) e por Cromatografia Gasosa acoplada a Espectrometria de Massa (CG-EM). No ensaio antifúngico, as frações foram diluídas em meio de cultura batata-dextrose-ágar (BDA) para obtenção das concentrações de Gasosa acoplada a Espectrometria de Massa (CG-EM). No ensaio antifúngico, as frações foram diluídas em meio de cultura batata-dextrose-ágar (BDA) para obtenção das concentrações de desafiante o fitopatógeno Colletotrichum musae isolado da banana. O maior rendimento foi obtido na fração hexânica (14,4\%), e a cumarina isolada dessa fração correspondeu a $3,4 \%$ desse rendimento. A fração diclorometânica foi a mais efetiva na redução do crescimento micelial do fitopatógeno, em todas as concentrações testadas.

\section{Evaluation of coumarin content and antifungal activity of Cumaru oil fractions}

Cumaruzeiros are neotropical trees originating from Central and South American countries. The fruits stand out for their commercial and phytotherapic potentialities, and their seeds, for over a century, have been marketed by Amazonian extractivists. This study aimed to analyze the coumarin content (1,2-benzopyrone) and the antifungal activity of oil fractions obtained from cumaru seeds produced in the municipality of Alenquer, Pará, Brazil. The fractions were obtained by successive cold extractions using Hexane P.A., Dichloromethane P.A., and $96 \%$ Ethy Alcohol P.A. The 1,2-benzopyran content in the fractions was chemically analyzed by Thin Layer Chromatography (CCD) and Mass Spectrometry Coupled Gas Chromatography (GC-MS). In the antifungal assay, fractions were diluted in potato-dextrose-agar (BDA) culture medium to obtain concentrations of $10 \%, 20 \%, 30 \%, 40 \%$ and $50 \%$ and poured into Petri dishes for phytopathen che effective in reducing the phytopathogen mycelial growth at all concentrations tested.

Keywords: Fungitoxic action; Alternative control; Dipteryx sp.; Fixed oils.

Topic: Microbiologia Agrícola e Ambiental

Reviewed anonymously in the process of blind peer
Received: 06/08/2018

Approved: 16/08/2018
Bruna Cristine Martins de Sousa

Universidade Federal do Oeste do Pará, Brasil

http://lattes.cnpq.br/2995856324286537

bruna0909martins@hotmail.com

Lauro Euclides Soares Barata (D)

Universidade Federal do Oeste do Pará, Brasil http://lattes.cnpq.br/1609747051706094

http://orcid.org/0000-0003-0909-769X

lauroesbarata@gmail.com

Caroline Gomes Macêdo (DD

Universidade Federal do Pará, Brasil

http://lattes.cnpq.br/1637502954956396

http://orcid.org/0000-0003-3715-1307

carolgomesmacedo@hotmail.com

\section{Sidney Santos Fraga (iD}

Universidade Federal do Oeste do Pará, Brasi http://lattes.cnpq.br/9282514002226634 http://orcid.org/0000-0002-3831-6639 sidneyssf643@gmail.com
Aline Aparecida München Kasper (iD) Universidade Federal do Oeste do Pará, Brasil http://lattes.cnpq.br/6191998314534966 http://orcid.org/0000-0003-2613-5125 aliny_@msn.com

\section{Katiane Araújo Lourido (iD}

Universidade Federal do Oeste do Pará, Brasil http://lattes.cnpq.br/7656086988352166 http://orcid.org/0000-0002-3923-1899 katialourido@gmail.com

Geomarcos da Silva Paulino (ic

Universidade Federal do Oeste do Pará, Brasil http://lattes.cnpq.br/4416864995277473

http://orcid.org/0000-0001-8255-0134 geomarcospaulino19@gmail.com

\author{
Everton Cristo de Almeida (iD) \\ Universidade Federal do Oeste do Pará, Brasil \\ http://lattes.cnpq.br/1713587609774692 \\ http://orcid.org/0000-0002-3039-5440 \\ evertonselva30@gmail.com \\ Adilson Sartoratto (iD) \\ Universidade Estadual de Campinas, Brasi \\ http://lattes.cnpq.br/2938768700584296 \\ http://orcid.org/0000-0002-1763-3715 \\ adilson@cpqba.unicamp.br \\ Denise Castro Lustosa (iD \\ Universidade Federal do Oeste do Pará, Brasil \\ http://lattes.cnpq.br/8533910667262644 \\ http://orcid.org/0000-0001-7448-9564 \\ denise.lustosa@ufopa.edu.br
}

DOI: 10.6008/CBPC2179-6858.2018.006.0008

\section{Referencing this:}

SOUSA, B. C. M.; BARATA, L. E. S.; MACÊDO, C. G.; FRAGA, S. S.; KASPER, A. A. M.; LOURIDO, K. A.; PAULINO, G. S.; ALMEIDA, E. C.; SARTORATTO, A.; LUSTOSA, D. C.. Avaliação do teor de Cumarina e atividade antifúngica de frações de Óleo de Cumaru. Revista IberoAmericana de Ciências Ambientais, v.9, n.6, p.63-69, 2018. DOI: http://doi.org/10.6008/CBPC2179-6858.2018.006.0008 


\section{INTRODUÇÃO}

Os frutos do cumaruzeiro (Dipteryx odorata) destacam-se quanto às potencialidades comerciais e fitoterápicas; suas favas, como são chamadas as sementes, possuem um perfume peculiar que lembra o da baunilha e o foin coupé e, historicamente, foram bastante procuradas para a extração de cumarina (principal composto ativo) para flavorizar tabacos na indústria de fumo e nas fábricas de perfumes (PESCE, 2009; ZOGHBI et al., 2000).

$\mathrm{Na}$ medicina popular, o extrato aquoso da casca do fruto de cumaru é utilizado como antiespasmódico e geralmente tônico no combate a tosses, gripes e problemas pulmonares (CARVALHO, 2009; PESCE, 2009; RIOS et al., 2011). A partir do cozimento dos frutos e das sementes, obtém-se um tipo de fortificante que age como um eficiente moderador dos batimentos cardíacos e respiratórios (CARVALHO, 2009; COINTE, 1947; LOUREIRO et al., 1979), além de atuar sobre o sistema nervoso cérebro-espinhal em razão do seu efeito anestésico e, apresentar propriedades diaforéticas e emenagogas (CARVALHO, 2009; PASTORE et al., 1998; PRANCE et al., 1975).

Esses produtos naturais por serem biodegradáveis, renováveis e conterem substâncias farmacológicas em potencial, também despertam interesse na descoberta de suas atividades microbiológicas (FERNANDES et al., 2011), destacando-se no que se refere ao controle alternativo de doenças que atacam uma grande variedade de culturas (CUNICO et al., 2006), como por exemplo, a antracnose, doença em póscolheita de maior ocorrência nas regiões tropicais e subtropicais, atingindo frutas como o mamão (Carica papaya), a manga (Mangifera indica) e a banana (Musa sp.), sendo causada por fungos do gênero Colletotrichum (LIMA FILHO et al., 2003).

A cultura da bananeira, cujos frutos são consumidos quase sempre in natura, sofre vários problemas fitossanitários (OLIVEIRA et al., 2016). Economicamente, Colletotrichum musae, causa prejuízos no campo e em pós-colheita, pois infecta os frutos imaturos por penetração direta da cutícula até os frutos maduros (COUTO et al., 2004). A planta com antracnose sofre intensa desfolha e seca de ramos, e os frutos formam lesões escuras e deprimidas. Com o progresso da doença, estas lesões aumentam de tamanho, tornando os frutos inviáveis para a exportação (TAVARES et al., 2005).

O método de controle mais utilizado para a antracnose é o químico. No entanto, estudos realizados com produtos naturais têm se mostrado eficazes no controle dessa doença em frutíferas, devido à ação fungitóxica, sendo úteis para as indústrias no desenvolvimento de futuros produtos biocompatíveis, seja como produto/componente in natura, ou como modelo para síntese ou semissíntese química de produtos com características tóxicas necessárias (MORAIS, 2009).

Negreiros et al. (2013), ao avaliar óleos essenciais no controle da antracnose da banana 'prata' e compará-los com o efeito do fungicida preconizado (tiabendazol), obteve a não depreciação dos frutos e redução da doença; Venturoso et al. (2010) destacou a ação do óleo de eucalipto (Eucalyptus citriodora) sobre Colletotrichum gloeosporioides em mamão; e Carnelossi et al. (2009) indicou atividade antifúngica para os óleos de capim-limão (Cymbopogon citratus) e menta (Mentha piperita). Nesse contexto, objetivou-se 
avaliar o teor de cumarina (1,2-benzopirona) das frações obtidas das sementes de cumaru e suas atividades antifúngicas sobre Colletotrichum musae, agente causal da doença antracnose em banana.

\section{METODOLOGIA}

Para obtenção das frações, as sementes produzidas no município de Alenquer (PA) foram pesadas (50g), trituradas e realizadas extrações sucessivas à frio segundo metodologia adaptada de Taube Junior et al. (2014). Os procedimentos ocorreram em triplicata, tendo como solventes hexano P.A., diclorometano P.A. e álcool etílico P.A. a 96\%, e duração de 48 horas para cada extração. Após evaporação do solvente, as frações foram armazenadas em frascos âmbar esterilizados. Os rendimentos foram calculados pela fórmula: [Massa do extrato $(\mathrm{g}) /$ Massa do material seco $(\mathrm{g})]$ x 100.

A 1,2-benzopirona (cumarina) foi isolada a partir da extração hexânica à frio, em triplicata. O óleo obtido foi submetido ao processo de cristalização pela adição de hexano, aquecimento dessa solução a $60^{\circ} \mathrm{C}$ e volatilização do solvente a temperatura ambiente, segundo metodologia adaptada de Taube Junior et al. (2014). Em seguida, as impurezas foram removidas por lavagem com hexano e filtração a vácuo em Funil de Büchner, e obtidos os cristais de cumarina. Verificou-se a pureza da substância isolada através do Ponto de Fusão, Cromatografia em Camada Delgada (CCD) e Cromatografia Gasosa acoplada a Espectrometria de Massa (CG-EM).

Para realização da análise por CCD foram utilizadas placas de alumínio (10 x 10cm) e sílica-gel 60 com indicador fluorescente e espessura da camada de 0,20 mm. Cada amostra hexânica de óleo que foi pesada (20mg), foi adicionado $1 \mathrm{~mL}$ de álcool etílico, homogeneizado, e aplicadas alíquotas de $10 \mu \mathrm{L}$ de seus volumes sobre a placa cromatográfica, à distâncias de 1,5cm cada. O padrão da 1,2-benzopirona e a cumarina isolada nas repetições foram pesadas à $10 \mathrm{mg}$, adicionados $1 \mathrm{~mL}$ de álcool metílico e aplicadas alíquotas de $10 \mu \mathrm{L}$ de seus volumes sobre as placas cromatográficas como descrito em Wagner et al. (2001).

O sistema consistiu de placas eluídas utilizando uma mistura contendo hexano: acetato de etila (80:20). Posteriormente, essas placas foram secas e reveladas com $p$-anisaldeído. Foram calculados os Fatores de Retenção (Rf) pela fórmula: $\mathrm{Rf}=\mathrm{h} / \mathrm{H}$, onde: $\mathrm{h}=$ Altura da amostra a partir do ponto de aplicação. $\mathrm{H}=$ Altura máxima da fase móvel (TAUBE JUNIOR et al., 2014).

Para CG-EM, utilizou-se cromatógrafo HP-6890, coluna capilar de HP-5MS (30m x 0,25mm x 0,25 $\mu \mathrm{m})$ e detector operando a $70 \mathrm{eV}$, varredura linear no intervalo de 30 a 500u.m.a. às condições cromatográficas temperatura do injetor $250^{\circ} \mathrm{C}$ e do detector $300^{\circ} \mathrm{C}$, hélio como gás de arraste $\left(1,0 \mathrm{~mL} . \mathrm{min}^{-1}\right)$ programação de temperatura $80^{\circ} \mathrm{C}$ a $280^{\circ} \mathrm{C}$ a uma taxa de $5^{\circ} \mathrm{C} \cdot \mathrm{min}^{-1}$ e injeção de $1 \mu \mathrm{L}$ das frações e cumarina. Os compostos foram identificados por comparação com a biblioteca NIST05. Os ensaios antifúngicos foram realizados utilizando o fungo Colletotrichum musae isolado de frutos de banana, do qual foram obtidas colônias axênicas para utilização nos experimentos.

Preparou-se soluções contendo as frações e água destilada esterilizada, na proporção de 1:1, sendo adicionados Polivinilpirrolidona (PVP), na concentração 1:4 (extrato: PVP). Após as diluições, essas soluções foram filtradas em Millipore de porosidade 0,22 $\mu \mathrm{m}$, e colocadas em meio Batata-Dextrose-Ágar (BDA), 
fundente (aproximadamente $45^{\circ} \mathrm{C}$ ), para obtenção das concentrações de $10 \% ; 20 \% ; 30 \% ; 40 \%$ e $50 \%$ (p:v). Após a adição das frações, os meios foram homogeneizados e vertidos em placas de Petri, onde depositouse, centralmente, discos de 0,4cm contendo micélios do fungo (PINTO et al., 2003).

Os desafiantes foram incubados a $25^{\circ} \mathrm{C}$, sob fotoperíodo de $12 \mathrm{~h}$. O controle consistiu do semeio do fungo em meio BDA sem adição das frações. O delineamento experimental foi inteiramente casualizado (DIC), em esquema fatorial, com quatro repetições. As avaliações foram realizadas medindo-se o diâmetro médio das colônias, diariamente, durante cinco dias. Foi considerada alta atividade antifúngica quando os extratos proporcionaram inibição igual ou superior a 50\% (VENTUROSO et al., 2011). Os dados foram analisados pelo software estatístico SisVar 5.6 e as médias comparadas pelo teste Tukey $(p \leq 0,05)$.

\section{DISCUSSÃO TEÓRICA}

O maior rendimento das frações das sementes de cumaru foi obtido na fração hexânica. A cumarina isolada da fração hexânica representou 3,4\% do seu rendimento (tabela 1). Para a 1,2-benzopirona cristalizada, constatou-se o ponto de fusão entre $68-70^{\circ} \mathrm{C}$, e pelo método de $\mathrm{CCD}$, confirmou-se o isolamento dessa substância nas aplicações 2,4 e 6, conforme se pode ver na figura $1 \mathrm{~A}$, devido à intensidade, coloração e igual fator de retenção $(0,52)$, quando comparadas com a 1,2-benzopirona sintética. Nas aplicações 3, 5 e 7 referentes aos óleos (figura $1 \mathrm{~A}$ ), além da cumarina simples, a placa revelada expôs manchas de coloração azulada (figura 1B, aplicações 3, 5 e 7), sugerindo a presença de ácidos graxos. Essa revelação também demonstrou que os isolados de 1,2-benzopirona não se encontram contaminados por ácidos graxos (Figura 1B, aplicações 2, 4 e 6).

Tabela 1: Rendimento médio das frações de óleo obtidas das sementes de cumaru por extrações sucessivas à frio.

\begin{tabular}{|l|c|c|c|}
\hline \multirow{2}{*}{} & \multicolumn{3}{|c|}{ Frações de óleo } \\
\cline { 2 - 4 } & Hexânica & Diclorometânica & Etanólica \\
\hline Massa & $7,2 \mathrm{~g}$ & $1,5 \mathrm{~g}$ & $3,6 \mathrm{~g}$ \\
\hline Rendimento & $14,4 \%$ & $3 \%$ & $7,2 \%$ \\
\hline Cumarina cristalizada & $1,7 \mathrm{~g}$ & - & - \\
\hline Rendimento da cumarina & $3,4 \%$ & - & - \\
\hline
\end{tabular}

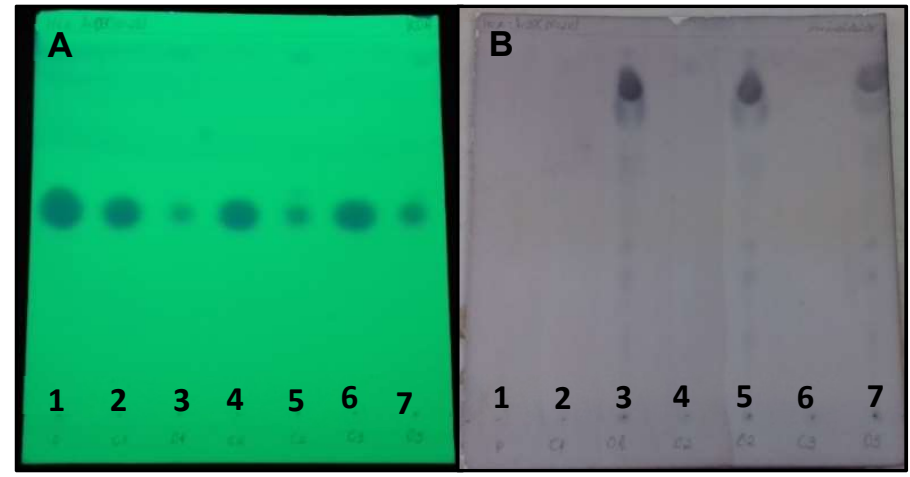

FIGURA 1: Placa de CCD eluída em mistura de hexano: acetato de etila (80:20): A: Cumaru (Dipteryx sp.) visualizada no comprimento de onda de $254 \mathrm{~nm}$; B: Cumaru (Dipteryx sp.) revelada com $p$-anisaldeído. 1 = Padrão (1,2-benzopirona sintética); 2 = Cumarina isolada, Repetição 1; 3 = Óleo, Repetição 1; 4 = Cumarina isolada, Repetição 2; 5 = Óleo, Repetição 2; 6 = Cumarina isolada, Repetição 3; 7 = Óleo, Repetição 3.

A análise por Cromatografia Gasosa acoplada a Espectrometria de Massa indicou com porcentagem relativa de $100 \%$ e tempo de retenção de 13,9 minutos, o isolamento da 1,2-benzopirona das sementes. A 
mesma porcentagem dessa substância foi encontrada quando realizada análise da fração hexânica íntegra. As frações diclorometânica e etanólica apresentaram dois constituintes que diferiram apenas nas porcentagens relativas, a 1,2-benzopirona, com 83,8\% na fração etanólica e a 3,4-dihidrocumarina, com 20,2\% na fração diclorometânica, que pode ser visualizada na tabela 2.

Tabela 2: Análise química das frações de óleo obtidas das sementes de cumaru por extrações sucessivas à frio.

\begin{tabular}{|l|c|c|c|}
\hline \multirow{2}{*}{} & \multicolumn{3}{|c|}{ Frações de óleo } \\
\cline { 2 - 4 } & Hexânica & Diclorometânica & Etanólica \\
\hline 1,2-benzopirona (Cumarina) & $100 \%$ & $79,8 \%$ & $83,8 \%$ \\
\hline 3,4-dihidrocumarina & - & $20,2 \%$ & $16,2 \%$ \\
\hline
\end{tabular}

Em relação à atividade antifúngica, houve diferença significativa para os fatores isoladamente (frações e concentrações), bem como para a interação entre eles $(p \leq 0,05)$. Considerando os fatores isoladamente, a fração diclorometânica e a concentração de $40 \%$ proporcionaram os menores diâmetros médios das colônias de $C$. musae.

Analisando a interação entre os fatores (frações $x$ concentrações), a fração hexânica proporcionou as maiores reduções no diâmetro de $C$. musae nas concentrações de 30, 40 e 50\%, que não diferiram estatisticamente entre si. Todas as concentrações da fração diclorometânica reduziram o crescimento do fitopatógeno avaliado, enquanto que, apenas a concentração de $10 \%$ da fração etanólica ocasionou redução no diâmetro médio da colônia do fitopatógeno em relação ao tratamento controle (tabela 3). As médias seguidas pelas mesmas letras minúsculas nas colunas e pelas mesmas letras maiúsculas nas linhas não diferem entre si pelo teste de Tukey $(p \leq 0,01)$.

Tabela 3: Diâmetro médio das colônias de Colletotrichum musae submetidas às diferentes concentrações das frações de óleo obtidas de sementes de cumaru produzidas em Alenquer (PA).

\begin{tabular}{|c|c|c|c|c|c|c|c|}
\hline \multirow{3}{*}{ Frações } & \multicolumn{6}{|c|}{ Diâmetro médio das colônias (cm) } & \multirow[b]{3}{*}{50} \\
\hline & \multicolumn{6}{|c|}{ Concentrações (\%) } & \\
\hline & Controle & PVP & 10 & 20 & 30 & 40 & \\
\hline Hexânica & $4,0 \mathrm{aA}$ & 4,1 aA & $4,0 \mathrm{aA}$ & $3,9 \mathrm{aA}$ & $3,8 \mathrm{bB}$ & $3,8 \mathrm{bB}$ & $3,8 \mathrm{bB}$ \\
\hline Diclorometânica & $4,0 \mathrm{aA}$ & $4,1 \mathrm{aA}$ & $3,7 \mathrm{bB}$ & $3,8 \mathrm{bB}$ & $3,7 \mathrm{bBC}$ & $3,5 \mathrm{cC}$ & $3,7 \mathrm{bBC}$ \\
\hline Etanólica & $4,0 \mathrm{aAB}$ & $4,1 \mathrm{aA}$ & $3,7 \mathrm{bC}$ & $3,9 \mathrm{abB}$ & $3,9 \mathrm{aB}$ & $3,9 \mathrm{aAB}$ & $3,9 \mathrm{aAB}$ \\
\hline \multicolumn{7}{|l|}{ CV (\%) } & \\
\hline
\end{tabular}

Legenda: PVP: Polivinilpirrolidona.

As cumarinas têm na natureza como representante mais simples a 1,2-benzopirona que foi isolada pela primeira vez de frutos de Dipteryx odorata, por Vogel, em 1820 (CORRÊA, 2014; SULLIVAN, 1982). São sintetizadas, principalmente, nas folhas, mas ocorrem em níveis mais altos nos frutos, seguido pelas raízes e caules. No entanto, mudanças sazonais e condições ambientais podem afetar a ocorrência das mesmas em várias partes da planta (OJALA, 2001).

Quanto ao maior rendimento de óleo e cumarina na fração hexânica, Baggio (2014) relatou em seu estudo que o $\mathrm{n}$-hexano foi o solvente que conseguiu extrair maior quantidade de cumarinas, provavelmente, devido ao fato destes compostos serem lipofílicos, ocorrendo assim maior afinidade química com solvente apolar. 
Corroborando com os dados obtidos no isolamento da cumarina simples em relação ao ponto de fusão e análises cromatográficas, Egan et al. (1990) inferiu que a 1,2-benzopirona possui massa molecular de $146,15 \mu$, ponto de fusão entre $68-70^{\circ} \mathrm{C}$, ponto de ebulição de $303^{\circ} \mathrm{C}$ e densidade de $0,94 \mathrm{~g} \cdot \mathrm{cm}^{-3}$. Bentes et al. (1981) indica que a composição de ácidos graxos no óleo de cumaru é bastante expressiva, sendo 6,6\% de ácido palmítico, 4,5\% de ácido esteárico, 47,3\% de ácido oleico, 21,6\% de ácido linoleico, 5,5\% de ácido linolênico, 6,2\% de ácido araquídico, 4,3\% de ácido beênico e 3,9\% de ácido lignocérico.

Em relação à presença do composto 3,4-dihidrocumarina nas frações diclorometânica e etanólica encontradas nesse trabalho, podemos destacar que, segundo Pesce (2009), as favas de cumaru do Pará são preparadas com menor cuidado e misturadas, o que podem influenciar diretamente na composição química e atividade biológica, em função da variedade de espécies inseridas no ambiente de coleta deste material.

A variação encontrada para a atividade antifúngica em relação às frações e concentrações avaliadas pode ser explicada por Souza (2005), onde relata que, a capacidade de diferentes produtos de origem vegetal em promover a redução ou o crescimento de fungos depende da sua composição química, que é diferente entre as espécies de plantas e influenciada pelas condições culturais, fatores climáticos e estágio de desenvolvimento da planta. Celoto et al. (2008), avaliaram 20 espécies de plantas e somente os extratos provenientes de espirradeira, eucalipto e melão de são caetano obtiveram porcentagem de inibição superior a $50 \%$ no controle de Colletotrichum gloeosporioides.

Oliveira et al. (2016) avaliando o efeito de óleos e extratos de alecrim pimenta, cravo-da-índia e eucalipto no crescimento micelial de C. musae, verificaram que os óleos de alecrim pimenta e cravo-da-índia inibiram em $100 \%$ o crescimento do fungo nas concentrações de $50 \mu \mathrm{L}$ e $100 \mu \mathrm{L}$, porém, o óleo de eucalipto não apresentou efeitos favoráveis, não havendo diferença estatística das concentrações com a testemunha.

\section{CONCLUSÕES}

O maior rendimento foi obtido na fração hexânica. A 1,2-benzopirona foi isolada das sementes de cumaru e identificada em todas as frações de óleo. Foram identificados por CG-EM os compostos 3,4dihidrocumarina nas frações diclorometânica e etanólica, além da cumarina simples. A fração obtida por extração diclorometânica foi a mais eficiente na redução do crescimento micelial de Colletotrichum musae.

\section{REFERÊNCIAS}

BAGGIO, S. O.. Extração de cumarinas de Pterocaulon balansae (Asteraceae). Monografia (Graduação em Farmácia) - Universidade Federal do Rio Grande do Sul, Porto Alegre, 2014.

BENTES, M. H. S.; SERRUYA, H.; ROCHA FILHO, G. N.. Análise dos óleos das amêndoas de duas leguminosas: Cumaru (Coumarouna odorata Aubl.) e olho de boi (Mucuna altissima). In: ENCONTRO DE PROFISSIONAIS DE QUÍMICA DA AMAZÔNIA, 2. Anais. São Luís, 1981.

CARNELOSSI, P. R.; SCHWAN-ESTRADA, K. R. F.; CRUZ, M. E. S.; ITAKO, A. T.; MESQUINI, R. M.. Óleos essenciais no controle pós-colheita de Colletotrichum gloeosporioides em mamão. Revista Brasileira de Plantas Medicinais, v.11, n.4, p.399-406, 2009. DOI: http://doi.org/10.1590/S1516$\underline{05722009000400007}$

CARVALHO, P. E. R.. Cumaru-ferro Dipteryx odorata. Brasília: Embrapa, 2009.

CELOTO, M. I. B.; PAPA, M. F. S.; SACRAMENTO, L. V. S.; CELOTO, F. J.. Atividade antifúngica de extratos de plantas a Colletotrichum gloeosporioides. Acta Scientiarum, v.30, n.1, p.1-5, 2008. 
COINTE, P.. Amazônia Brasileira III: Árvores e Plantas Úteis (indígenas e aclimatadas). 2 ed. Rio de Janeiro: Brasiliana, 1947.

CORRÊA, A. J. C.. Análise comparativa de atividades antimicrobiana e citotóxica de extratos brutos e frações do rizoma de Alpinia zerumbet (PERS.) B.L. BURTT. \& R.M. SM. com três cumarinas sintéticas. Dissertação (Mestrado em Ciências Biológicas) - Universidade Federal de Pernambuco, Recife, 2014.

COUTO, E. F. E.; MENEZES, M.. Caracterização fisiomorfológica de isolados de Colletotrichum musae. Fitopatologia Brasileira, v.29, n.4, p.406-412, 2004. DOI: http://doi.org/10.1590/S0100-41582004000400008

CUNICO, M. M.; CARVALHO, J. L. S.; ANDRADE, C. A.; MIGUEL, O. G.; MIGUEL, M. D; AUER, C. G.; GRIGOLETTI JÚNIOR, A; CÔCCO, L. C.; YAMAMOTO, C. I.. Atividade antifúngica de extratos brutos de Ottonia martiana Miq., Piperaceae. Visão Acadêmica, v.7, p.15-24, 2006. DOI: http://doi.org/10.5380/acd.v7i2.9024

EGAN, D.; O'KENNEDY, R.; MORAN, E.; COX, D.; PROSSER, E.; THORNES, R. D.. The Pharmacology, Metabolism, Analysis, and Applications of coumarin and coumarin-related compounds. Drug Metabolism Review, v.22, n.5, p.503-529, 1990. DOI: http://doi.org/10.3109/03602539008991449

FERNANDES, O. C. C.; CARNEIRO, A. L. B.; SILVA, A. B.; FEITOSA, K. B.; LEMOS, R. A.; FILHO, R. F. C.; SILVA, J. C.. Compostos Naturais e Atividade Antimicrobiana. In: TEIXEIRA, M. F. S.; SILVA, T. A.; PALHETA, R. A.; CARNEIRO, A. L. B.; ATAYDE, H. M.. Fungos da Amazônia: uma riqueza inexplorada (Aplicações Biotecnológicas). Manaus: EDUFAm, 2011. p.82-103.

LIMA FILHO, R. M.; OLIVEIRA, S. M. A.; MENEZES, M.. Caracterização enzimática e patogenicidade cruzada de Colletotrichum spp. associados a doenças de pós-colheita. Fitopatologia Brasileira, v.28, p.620-625, 2003. DOI: http://doi.org/10.1590/\$0100-41582003000600007

LOUREIRO, A. A.; SILVA, M. F.; ALENCAR, J. C.. Essências madeireiras da Amazônia. 2 ed. Manaus: INPA, 1979. MORAIS, L. A. S.. Óleos essenciais no controle fitossanitário. In: BETTIOL, W.; MORANDI, M. A. B.. Biocontrole de doenças de plantas: uso e perspectivas. Jaguariúna: Embrapa, 2009. p.137-150.

NEGREIROS, R. J. Z.; SALOMÃO, L. C. C.; PEREIRA, O. L.; CECON, P. R.; SIQUEIRA, L. D.. Controle da antracnose na pós-colheita de bananas-prata com produtos alternativos aos agrotóxicos convencionais. Revista Brasileira Fruticultura, v.35, n.1, p.51-58, 2013.

OJALA, T.. Biological Screening of Plant Coumarins. Dissertação (Mestrado em Farmacologia) - Universidade do Helsinki, Finlândia, 2001.
OLIVEIRA, E. S.; VIANA, F. M. P.; MARTINS, M. V. V. Alternatives to fungicides in the control of banana anthracnose. Summa Phytopathologica, v.42, n.4, p.340350, 2016. DOI: http://doi.org/10.1590/0100-5405/2000

PASTORE, J. F.; BORGES, V. L.. Produtos Florestais NãoMadeireiros: Processamento, coleta e comercialização. Brasília: UnB, 1998.

PESCE, C.. Oleaginosas da Amazônia. 2 ed. Belém: MPEG, 2009.

PINTO, T. J. A.; KANEKO, T. M.; OHARA, M. T. Controle biológico de qualidade de produtos farmacêuticos, correlatos e cosméticos. 2 ed. São Paulo: Atheneu, 2003.

PRANCE, G. T.; SILVA, M. F.. Árvores de Manaus. Manaus: INPA, 1975.

RIOS, M. N. S.; PASTORE JUNIOR, F.. Plantas da Amazônia 450 espécies de uso geral. Brasília: UnB, 2011.

SOUZA, S. M.. Atividade antibacteriana de cumarinas naturais e derivados. Dissertação (Mestrado em Biotecnologia) - Universidade Federal de Santa Catarina, Florianópolis, 2005.

SULLIVAN, G.. Occurrence of umbelliferone in the seeds of Dipteryx odorata (Aubl.) Willd. Journal of Agricultural and Food Chemistry, v.30, n.3, p.609-610, 1982. DOI: http://doi.org/10.1021/jf00111a051

TAUBE JUNIOR., P. S.; CASTRO, K. C. F.; BARATA, L. E. S.. Experimentos de Química. Santarém: UFOPA, 2014.

TAVARES, G. M.; SOUZA, P. E.. Efeito de fungicidas no controle in vitro de Colletotrichum gloeosporioides, agente etiológico da Antracnose do Mamoeiro (Carica papaya L.) Ciência e Agrotecnologia, v.29, n.1, p.52-59, 2005. DOI: http://doi.org/10.1590/S1413-70542005000100006

VENTUROSO, L. R.; BACCHI, L. M. A.; GAVASSONI, W. L.; CONUS, L. A.; PONTIM, B. C. A.; BERGAMIN, A. C.. Influência de diferentes metodologias de esterilização sobre a atividade antifúngica de extratos aquosos de plantas medicinais. Revista Brasileira de Plantas Medicinais, v.12, n.4, p. 499-505, 2010. DOI: http://doi.org/10.1590/S1516$\underline{05722010000400014}$

VENTUROSO, L. R.; BACCHI, L. M. A.; GAVASSONI, W. L.; CONUS, L. A.; PONTIM, B. C. A.; BERGAMIN, A. C.. Atividade antifúngica de extratos vegetais sobre o desenvolvimento de fitopatógenos. Summa Phytopathologica, v.37, n.1, p.18-23, 2011. DOI: http://doi.org/10.1590/S010054052011000100003

WAGNER, H.; BLADT, S.. Plant drug analysis: a thin layer chromatography atlas. 2 ed. Berlin: Springer, 2001. ZOGHBI, M. G. B.; ANDRADE, E. H.; MAIA, J. G. S.. Aroma de flores da Amazônia. Belém: MPEG, 2000.

A CBPC - Companhia Brasileira de Produção Científica (CNPJ: 11.221.422/0001-03) detém os direitos materiais desta publicação. Os direitos referem-se à publicação do trabalho em qualquer parte do mundo, incluindo os direitos às renovações, expansões e disseminações da contribuição, bem como outros direitos subsidiários. Todos os trabalhos publicados eletronicamente poderão posteriormente ser publicados em coletâneas impressas sob coordenação da Sustenere Publishing, da Companhia Brasileira de Produção Científica e seus parceiros autorizados. Os (as) autores (as) preservam os direitos autorais, mas não têm permissão para a publicação da contribuição em outro meio, impresso ou digital, em português ou em tradução. 